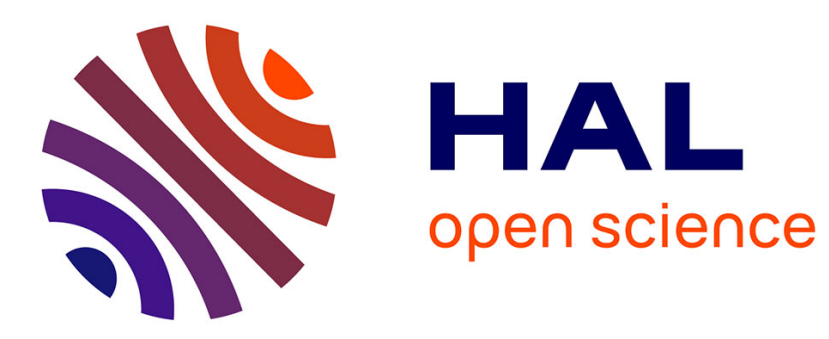

\title{
Towards Method Time Measurement Identification Using Virtual Reality and Gesture Recognition
}

\author{
Abdelkader Bellarbi, Jean Pierre Jessel, Laurent da Dalto
}

\section{To cite this version:}

Abdelkader Bellarbi, Jean Pierre Jessel, Laurent da Dalto. Towards Method Time Measurement Identification Using Virtual Reality and Gesture Recognition. IEEE International Conference on Artificial Intelligence \& Virtual Reality (AIVR 2019), Dec 2019, San Diego, California, United States. hal-02413200

\author{
HAL Id: hal-02413200 \\ https://hal.science/hal-02413200
}

Submitted on 16 Dec 2019

HAL is a multi-disciplinary open access archive for the deposit and dissemination of scientific research documents, whether they are published or not. The documents may come from teaching and research institutions in France or abroad, or from public or private research centers.
L'archive ouverte pluridisciplinaire HAL, est destinée au dépôt et à la diffusion de documents scientifiques de niveau recherche, publiés ou non, émanant des établissements d'enseignement et de recherche français ou étrangers, des laboratoires publics ou privés. 


\title{
Towards Method Time Measurement Identification Using Virtual Reality and Gesture Recognition
}

\author{
Abdelkader Bellarbi ${ }^{1}$, Jean-Pierre Jessel ${ }^{2}$, Laurent Da Dalto ${ }^{3}$ \\ ${ }^{1,2}$ IRIT, University of Toulouse, France \\ ${ }^{3}$ Mimbus, France \\ 19abdelkader.bellarbi@irit.fr, ${ }^{2}$ jean-pierre.jessel@irit.fr, ${ }^{3}$ laurent.dadalto@,mimbus.com
}

\begin{abstract}
Methods-Time Measurement (MTM) is a predetermined motion time system that is used primarily in industrial settings to analyze the methods used to perform any manual operation. In this paper, we introduce a system for automatic generation of MTM codes using only head and both hands 3D tracking. Our approach relies on the division of gestures into small elementary movements. Then, we built a decision tree to aggregate these elementary movements in order to generate the realized MTM code.
\end{abstract}

The proposed system does not need any pre-learning step, and it can be useful in both virtual environments to train technicians and in real cases with industrial workshops to assist experts for MTM code identification. Obtained results are satisfying and promising. This work is in progress, we plan to improve it in the near future.

Keywords- Methods-Time Measurement (MTM), Gesture Recognition, 3D Tracking, Virtual Reality.

\section{INTRODUCTION}

The production line's designing process, involves several steps, including the development of operating procedures. For this, the designer based mainly on the temporal aspect. Indeed, the objective is to ensure that the duration of the tasks assigned to each operator does not exceed the time previously defined by the production objectives. A second aspect that is important to take into account is the ergonomic work situation, in order to ensure operator comfort and avoid health problems due to poor working conditions.

In this sense, work analysis methods were taken into use in the industrialized countries on a larger scale since the 1930s [1]. Thus, the predetermined time systems make it possible to assign, a priori, durations associated with the elementary action execution such as reaching, grasping, placing, pressing, walking, etc. The times attributed to these actions vary notably according to the distance of movement, the difficulty to carry out the action and the effort exerted by the operator.

Among the most famous of this kind of systems is Method Time Measurement (MTM). MTM was developed by Maynard in the United States [2]. This method, serves as an instrument for the formal modelling, analysis, planning and design of work systems. It analyzes the methods used to perform any manual task and set the standard time in which a worker should complete that task.

MTM consists of various methods such as MTM-1, MTM2, MTM-UAS and MTM-MEK that may be utilized depending on the characteristics of the underlying manual work process [3]. For the production of medium to large product series (characterized by e.g. moderate cycle times, several repetitions), the MTM-UAS method may be applied as it ensures a relatively low effort regarding the process analysis. This can be realized by comprising numerous different motions within relatively, long single motion sequences (e.g. reaching, grasping, positioning and releasing an object).

MTM-UAS offers the possibility to deduce the weaknesses of work processes in a more direct and concise way. In addition, the use of standard basic movements is a tool for automatically detecting different motion sequences by identifying the typical characteristics of each sequence of movements. Therefore, MTM-UAS serves as the basis for performing time studies automatically by identifying time data and process modules.

However, the observation of technicians and the generation of MTM codes are still done manually by experts. Most of existing software are to facilitate recording, management and reports generation.

In this paper, we propose to automate this practice using a motion capture system that will allow us to analyze the movements of a technician in exercise or simulation, in order to automatically generate the MTM-UAS codes.

This paper is organized as follows. In section II, we present a brief state of the art of the different existing MTM analyses systems. In section III, we describe our proposed approach. System implementation and some results are presented in section IV. Finally, conclusions are drawn and future plans discussed.

\section{RELATED WORKS}

Since the works of Frank Bunker Gilbreth and then Asa Bertrand Segur in the 1920s, numerous time measurement systems have appeared such as MTS (Motion Time Survey, 1928). WF (Work Factor, 1936). MTM (Methods Time Measurement, 1948 for the initial MTM-1 version, 1965 for the second version MTM-2, and from 1975 to 1984 for the MTM-UAS, MTM-MEK and MTM-SAM versions). MODAPTS (Modular Arrangement of Predetermined Time Standards, 1966) and MOST (Maynard Operation Sequence Technique, 1980) [4]. These different versions appeared in order to adapt to changes in production methods.

From the 1990s, with the development of computer science, several software have been developped in order to help MTM experts. These software represent complementary tools for the experts to record workers motions, to input the observed MTM codes and to process these data in order to improve time and working conditions and to avoid any potential risk for the operators by taking into consideration the cycle time and the physical charge associated with the planned operating modes. Thus, the Motion Analysis and Index Derivation (MAID) software developed by Kuhn and Laurig [5] to extract from the MTM codes percentages of targeted 
cycle times, using the hands, arm and trunk, but also: effort, visual control, precision. EMMA software [6] aimed to minimize the cycle time and maximizing criteria such as the proportions of Operations performed in the field of view (no head movement) and the proportions of Operations performed using both hands. For MTM time studies, it suffices to observe a cycle of work content. However, it takes up to 200 times the observation time to perform the analysis, depending on the level of the MTM method. The duration of the analysis depends on the experience of the employee and requires extensive training in MTM.

In addition, ergonomic evaluators are integrated into this kind of software. Thus, in 1993 appeared ErgoMost combining a predetermined time analysis with an ergonomic evaluator that takes into account risk factors such as strength, posture, and vibration. ErgoMost provides risk assessment for the neck, upper limbs, lower limbs and back [7].

However, these software do not allow an automatic generation of MTM codes, experts have to observe and input MTM codes manually. The use of computer vision-based approaches for gestures recognition might be useful for an automatic generation of MTM codes $[8,9,10]$.

Recently, Benter and Kuhlang [11] proposed an approach to detect body motions in accordance to MTM-1 using motion capture data from 3D cameras. In [12], the authors proposed an automatic generation of the MTM-1 code from motion capture data using convolutional neural network.

Both approaches seem interesting, in the sense that they are based on gesture recognition in order to generate the MTM code. However, they require full visibility of the operator by the motion capture systems, which is often not possible. Objects may obscure the line of sight between the camera and the worker body. Then, either it does not detect the joints or it calculates faulty coordinates. Furthermore, even with an unobstructed view, it does not always interpret the 3D data correctly.

In this paper, we propose an approach for automatic generation of MTM-UAS codes by only tracking the head and the two hands. Thus, we may use this system in real situation with workstations as well as in virtual reality simulation. In addition, the proposed technique does not require any training or learning step. In the following, we describe our proposed system.

\section{PROPOSED APPRAOCH}

\section{A. Setup Design}

In order to reach the mentioned aim, we first designed a virtual environment to simulate the technician workstation, for that, we built a setup which composed of a virtual reality platform (HTC Vive). Replication of the real workplaces allows to adjust system parameters and to represent various tasks in all workplaces of woodworking. In order to maintain the naturalness of the replication movements, we have designed the equipment, tools, materials and the environment in a way so that they are as close as possible to the actual workplaces (Figure 1).

As a result, replicas are equipped with professional tools (saw, hammer, drill ...). The goal is to cover all basic movements according to MTM-UAS and their corresponding forms.

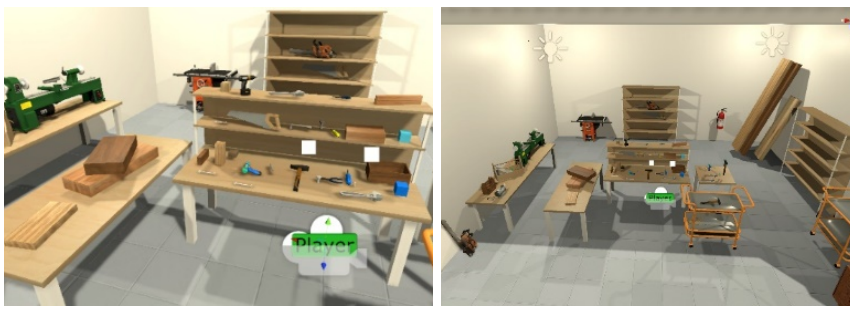

Fig. 1. The designed 3D environment to simulate a carpentry workshop

\section{B. Motion Analysis and MTM-UAS Codes Recognition}

The MTM-UAS is based on seven (7) basic movements, we can group them into body movements like walk and kneel, hands movements like operate and place, and eyes movements like visual control. Each movement is defined by a symbol. Table 1 illustrates these seven basic movements.

TABLE I. DESCRIPTION OF MTM-UAS BASIC MOVMENTS

\begin{tabular}{|c|c|c|c|}
\hline \multicolumn{2}{|c|}{$\begin{array}{l}\text { Basic MTM-UAS } \\
\text { Movements }\end{array}$} & \multirow{2}{*}{ 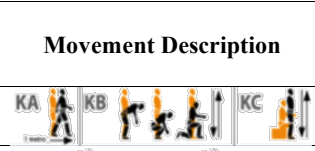 } & \multirow{2}{*}{$\begin{array}{c}\begin{array}{c}\text { Symbol } \\
\text { (First } \\
\text { Character) }\end{array} \\
\mathrm{K} \\
\end{array}$} \\
\hline $\begin{array}{l}\text { Body } \\
\text { Movements }\end{array}$ & Body Motion & & \\
\hline \multirow{5}{*}{$\begin{array}{l}\text { Hands } \\
\text { Movements }\end{array}$} & Get and Place & 8 & A \\
\hline & Handle & & $\mathrm{H}$ \\
\hline & Place & & $\mathrm{P}$ \\
\hline & Cycle Motion & & Z \\
\hline & Operate & & B \\
\hline $\begin{array}{l}\text { Eye } \\
\text { movement }\end{array}$ & Visual Control & & V \\
\hline
\end{tabular}

These symbols (characters) are followed by other characters and numbers according to some details, like for example the precision of the action, the mass of the handled object, or the distance traveled by the hand. Hence, according to these details, each MTM-UAS code has a predetermined time, which is defined by the TMU (time measurement unit). Where: 1 TMU = 36 millisecondes; 1 hour $=100,000$ TMU.

The total number of MTM-UAS codes is 29 codes. Figure 1 illustrates the different MTM-UAS codes with their predetermined time, as defined by International MTM Association [13].

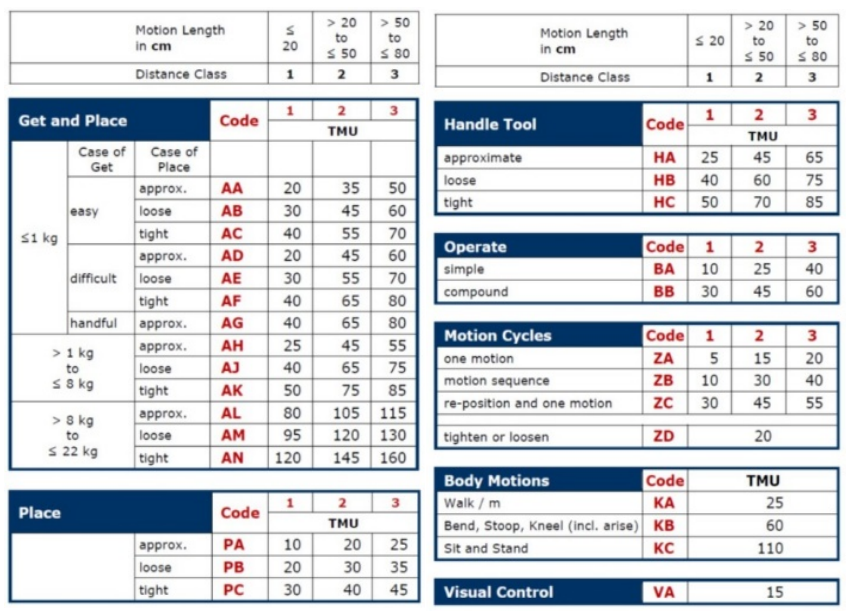

Fig. 2. MTM-UAS codes [12] 


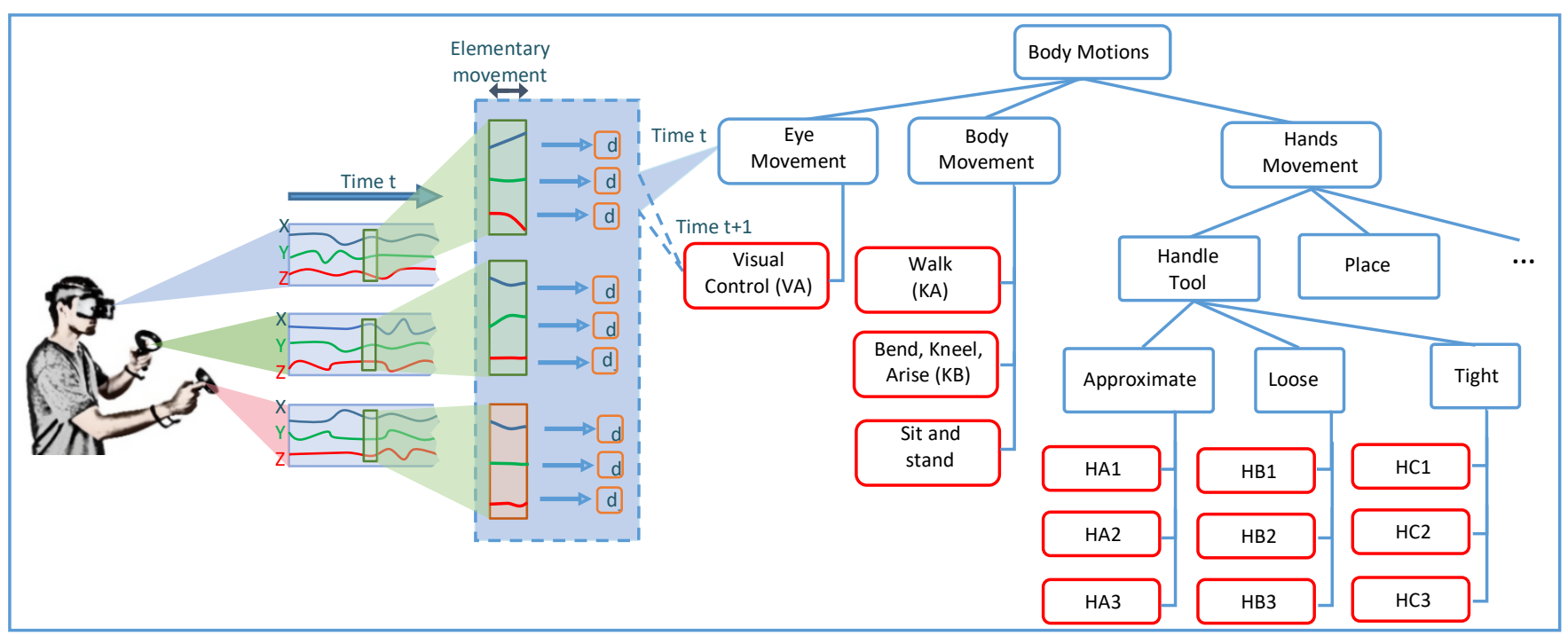

Fig. 3. Description of the proposed approach

In order to allow the recognition of all these codes, we proposed a decision tree-based approach. Therefore, we created a tree by grouping the motions according to their origin (body, hands and eyes) then we generated from each branch other detailed movements according to the mentioned MTM-UAS parameters in Figure 2.

The leave nodes of this tree represent the MTM-UAS codes. Each internal node of the tree contains specific data about the two hands and the head namely $3 \mathrm{D}$ position, $3 \mathrm{D}$ rotation and time.

Thereafter, we implemented an algorithm that, at each time $t$, captures data of both hands and head, and extracts from each one small sequence on movement (elementary movement) then compares them to data in the tree in order to decide which branch must follow until it arrives to a leave node (MTM-UAS code). Figure 3 gives a description of this approach. The calculation of elementary movement helps to estimate the hands motion acceleration and deceleration that used to detect the precision of the movement. After a series of tests, we fixed the sequences length by 5 TMU.

Once a correct MTM code is detected, the algorithm restarts from root node in order to detect another MTM-UAS code.

\section{IMPlENTAION, TEST AND Discussion}

We implemented our proposed system under Visual Studio C\# 2017 and Unity3D version 2018.3.3 running on a Windows PC with Intel Xeon 4410. We used an HTC VIVE Pro for virtual environment visualization and interaction, as well as for motion capture (the two Vive Controllers for both hands and the HMD for the head). For real cases, we can use VIVE Trackers or reflective markers with infrared cameras for head and hands tracking.

In order to test and evaluate our prototype, we proposed the following woodworking scenario: the worker gets a piece of wood from his left (mass: $4 \mathrm{~kg}$, distance $60 \mathrm{~cm}$ ) and places it on the table front of him. Then, he uses the saw on the shelf in front of him to saw the piece of wood ( 10 times). He gets the electric drill in front of him and drills the piece of wood (Figure 4). Then, He controls the drilled wood. Finally, he gets that piece wood and walks to the table on his right to place it.

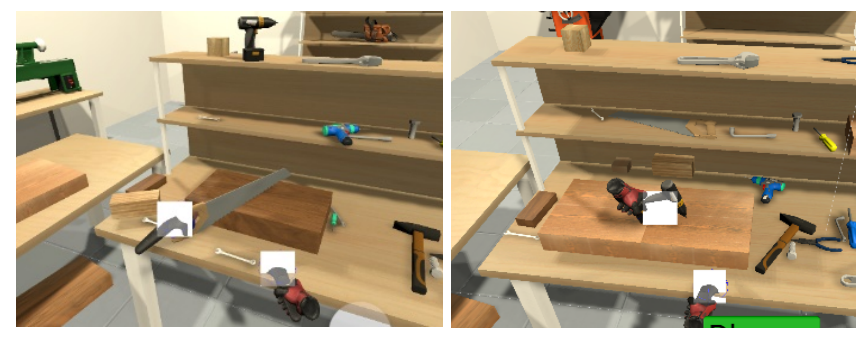

Fig. 4. Exemple of a worker performing some actions of the scenario.

We tested this scenario with 10 participants and we generated the MTM-UAS codes using the proposed technique. Table 2 shows the obtained results of five participants among ten (false detection is in Bold), as well as the codes given by an expert (Groundtruth). For the other 5 participants, the system detected correctly their motions, and generated exactly their MTM-UAS codes.

TABLE II. RESULTS OF MTM CODES DETECTION

\begin{tabular}{|l|c|c|c|c|c|c|}
\hline \multirow{2}{*}{$\begin{array}{l}\text { Movement } \\
\text { Description }\end{array}$} & \multirow{2}{*}{$\begin{array}{c}\text { Grou } \\
\text { nd. }\end{array}$} & \multicolumn{5}{|c|}{ Detected codes } \\
\cline { 4 - 7 } & & $\begin{array}{c}\text { Part. } \\
\mathbf{1}\end{array}$ & $\begin{array}{c}\text { Part. } \\
\mathbf{2}\end{array}$ & $\begin{array}{c}\text { Part. } \\
\mathbf{4}\end{array}$ & $\begin{array}{c}\text { Part. } \\
\mathbf{7}\end{array}$ & $\begin{array}{c}\text { Part. } \\
\mathbf{8}\end{array}$ \\
\hline $\begin{array}{l}\text { Get and place the } \\
\text { piece of wood }\end{array}$ & AH3 & AH3 & AH2 & AH3 & AH3 & AH3 \\
\hline $\begin{array}{l}\text { Get the saw and } \\
\text { place it on the wood }\end{array}$ & HB2 & HB2 & HB2 & AC2 & HB2 & HB2 \\
\hline $\begin{array}{l}\text { Cut the wood (10 } \\
\text { times) }\end{array}$ & $\begin{array}{c}\text { ZB1 } \\
(x 10)\end{array}$ & $\begin{array}{c}\text { ZB1 } \\
(x 10)\end{array}$ & $\begin{array}{c}\text { ZB1 } \\
(x 10)\end{array}$ & $\begin{array}{c}\text { ZB2 } \\
(x 10)\end{array}$ & $\begin{array}{c}\text { ZB1 } \\
(x 10)\end{array}$ & $\begin{array}{c}\text { ZB2 } \\
(x 10)\end{array}$ \\
\hline $\begin{array}{l}\text { Get the drill and } \\
\text { place it on the wood }\end{array}$ & HC2 & HC2 & HC2 & HC2 & HC2 & HA2 \\
\hline $\begin{array}{l}\text { Drill the wood } \\
\text { (Operate) }\end{array}$ & $\begin{array}{c}\text { BA1+ } \\
\text { PT }\end{array}$ & $\begin{array}{c}\text { BA1+ } \\
\text { PT }\end{array}$ & $\begin{array}{c}\text { BA1+ } \\
\text { PT }\end{array}$ & $\begin{array}{c}\text { BA1+ } \\
\text { PT }\end{array}$ & $\begin{array}{c}\text { BA1+ } \\
\text { PT }\end{array}$ & $\begin{array}{c}\text { BA1 } \\
+P T\end{array}$ \\
\hline Get the drilled wood & AH2 & AH2 & AH2 & AH2 & AH2 & AH2 \\
\hline Control it & VA & null & VA & VA & null & VA \\
\hline Walk to the table & KA & KA & KA & KA & KA & KA \\
\hline Place the wood & PA2 & PA2 & PA2 & PA2 & PA2 & PA2 \\
\hline
\end{tabular}

We note that some actions cannot be detected by this algorithm, namely "Operate" or "Processing Time PT". Thus, we implemented them as events in VR simulation. In real cases, we should add a physical event trigger to detect these actions.

Nevertheless, the proposed algorithm could detect and generate correctly up to $94 \%$ of codes without counting the codes Operate and Processing Time. It generated false 
detection only 5 times among the 80 motions done by the 10 participants.

The weak point of this technique is that it rejects or falsely detects an action if the worker does another gesture (eg. scratching, adjusting glasses) while performing an MTM motion.

\section{CONClustion}

In this paper, we introduced an approach for MTM-UAS code automatic generation. This technique is based only on head and hands positions, and it does not require any learning step. In addition, the proposed system can be used in real cases, as well as in virtual simulation for technicians training.

Evaluation done for this system with participants using a virtual simulation of carpentry workshop led to good results in terms of MTM-UAS codes recognition, which are validated by MTM experts. Thus, this system might be useful in industrial workshops to assist experts for MTM code identification and to reduce the processing time.

In the near future, we will improve the recognition algorithm and perform tests in real cases. On the other hand, we plan to spread this work to introduce ergonomic and health factors study.

\section{ACKNOWLEDGMENT}

This work is part of VILCANIZER Project, funded by the Occitanie Region in France.

The authors would like to thank M. Alain Extramiana, CEO of Amber Innovation and member of the France MTM Association, for his help as an expert of MTM.

\section{REFERENCES}

[1] Laring, J., Forsman, M., Kadefors, R., Et Al. MTM-based ergonomic workload analysis. International journal of Industrial ergonomics, 2002, vol. 30, no 3, p. 135-148.

[2] Maynard, Harold B., Gustave James Stegemerten, and John L. Schwab. "Methods-time measurement.", 1948.

[3] Karger, Delmar W., and Franklin H. Bayha. Engineered work measurement: the principles, techniques, and data of methods-time measurement background and foundations of work measurement and methods-time measurement, plus other related material. Industrial Press Inc., 1987.

[4] Sumanth, D.J.: Productivity Engineering and Management: Productivity Measurement, Evaluation, Planning, and Improvement in Manufacturing and Service Organizations. McGraw-Hill, New York, 1984.

[5] Kuhn, FRANK M., and W. O. L. F. G. A. N. G. Laurig. "Computeraided workload analysis using MTM." Computer-Aided Ergonomics: a Researchers Guide. Taylor and Francis, London (1990).

[6] Braun, W. J., R. Rebollar, and E. F. Schiller. "Computer aided planning and design of manual assembly systems." International journal of production research 34.8 (1996): 2317-2333.

[7] Zandin, Kjell B., et al. "ErgoMOST: An engineer's tool for measuring ergonomic stress." OCCUPATIONAL SAFETY AND HEALTHNEW YORK- 27 (1996): 417-430.

[8] Chen, Chen, Roozbeh Jafari, and Nasser Kehtarnavaz. "A survey of depth and inertial sensor fusion for human action recognition." Multimedia Tools and Applications 76.3 (2017): 4405-4425.

[9] Bellarbi, Abdelkader, Benbelkacem, Samir, Zenati-Henda, Nadia, et al. Hand gesture interaction using color-based method for tabletop interfaces. In : 2011 IEEE 7th International Symposium on Intelligent Signal Processing. IEEE, 2011. p. 1-6.

[10] Bellarbi, Abdelkader. Vers l'immersion mobile en réalité augmentée: une approche basée sur le suivi robuste de cibles naturelles et sur l'interaction 3D. (Toward mobile immersion in augmented reality: An approach based on robust natural feature tracking and 3D interaction.). 2017. Thèse de doctorat. University of Évry Val d'Essonne, France.

[11] Benter, Martin, and Peter Kuhlang. "Analysing Body Motions Using Motion Capture Data." International Conference on Applied Human Factors and Ergonomics. Springer, Cham, 2019.

[12] Burggräf, Peter, et al. "Automation Configuration Evaluation in Adaptive Assembly Systems Based on Worker Satisfaction and Costs." International Conference on Applied Human Factors and Ergonomics. Springer, Cham, 2019.

[13] International MTM Association : http://mtm-international.org/. 